lower hydrocarbons. It is clear that it is possible to look forward to the time when the petroleum industry will furnish the starting-out materials for a whole range of products so diverse as ethylene glycol-the familiar anti-freeze in the motor-car; sulphur from the crude gases at the oilfields; synthetic motor fuel prepared from methane oxidized into a liquid fuel ; the isomerization of normal paraffins; explosives such as T.N.T. (actually in fact produced in 1916); synthetic rubber, which is got by intensive polymerization of ethylene; high polymers of value in increasing the viscosity of lubricants ; a whole range of derivatives of the aromatic hydrocarbons obtained by pyrolysis or by the cyclization and aromatization of straight chain paraffins-resins and plastics from the polymerization products of olefines such as iso-butene; acetylene by the dehydrogenation of methane; ether and ketones as solvents and high anti-knock fuel; alcohols, esters and a whole range of solvents through the halogen derivatives of paraffins; and the very striking synthesis of glycerol from propylene. The vast synthetic chemical industry based on coal tar is familiar to all. The new industry, based on petroleum, is certain to outstrip it in the magnitude of its operation and the variety of its products.

\title{
FORMS OF SOCIETY AND EUROPEAN RULE IN AFRICA
}

$\mathrm{F}^{\mathrm{o}}$ $\mathrm{R}$ some time now it has been evident that a more intensive study of the political institutions and systems of native Africa was an increasingly urgent necessity. New and more searching methods of investigation have brought out the weaknesses and misconceptions of the older material, while of the more recent accounts of African economy complying with the standards of modern research, the extent is inadequate for the requirements of comparative study on the lines laid down in the development of sociological theory as applied in the study of the simpler societies. In such studies African political institutions will ultimately assume a place of importance, for they range from forms which ally themselves to those regarded as among the more primitive in the constitution of human societies, to those which in their extent and organization have been pronounced worthy to rank as great kingdoms and even empires, though of barbaric type, such as the West African emirates. In these, as well as in the details of the adjustment of social forces in the less advanced societies, there is abundant evidence of the political genius of Africa, which is not without its lessons for the study of more advanced communities.

Apart from the requirements of scientific and comparative study, there is a practical reason why more detailed and intensive investigation should be undertaken. The adoption of Indirect Rule through out the greater part of British Africa, and the possibility that other Colonial powers; in that co-operation in native administration to which we are pledged, may wish to assimilate their methods in some degree to those of British administration, render it imperative that the application of the principle of utilizing and adapting native institu- tions to the requirements of European control should be based upon precise knowledge of the nature of those institutions, and even more important, of the consequences and implications of any changes or adaptations in the native social and political relations inevitable under the impact of European control. This is all the more important as the effects of social disharmony extend their ramifications beyond the machinery for the preservation of law and order to provinces of amelioration and reform affecting the land, its utilization and preservation in good heart, hygiene, the well-being and education of the individual, his employment, the health of his stock and the like.

While the anthropologist in dealing with political and social institutions is concerned solely with scientific and objective study of the facts, it is inevitable that maladjustments and misunderstandings which arise out of European contacts and control should come under his notice. From these maladjustments even Indirect Rule is not exempt. It is, in fact, well known that both misunder. standing and friction have arisen from insufficient grounding in knowledge of the facts in certain situations, no preliminary or an insufficiently intensive survey having preceded introduction of this system of rule, or administrative co-operation. Too great reliance has been placed upon an assumed universality of the authority of the chief in African society ; and this has been allowed to warp judgment in assessing the bearing of facts not always perfectly understood. Comparatively unimportant individuals have been given official status, while the real seat of tribal authority, sometimes with native connivance, functions undiscerned behind a veil. In the result, what emerges is not Indirect Rule but a purely British bureaucratic system. 
This applies also under the French administrative system, for which its admirers have sometimes claimed that it approaches Indirect Rule without some of its more obvious disadvantages.

Something more than a beginning-indeed a substantial contribution towards the detailed anthropological survey of African societies which should form the basis of future post-War administration in Africa-has been made in a volume issued by the International Institute of African Languages and Cultures under the joint editorship of Dr. E. E. Ewans-Pritchard and Dr. M. Fortes*, with a foreword by Prof. A. R. Radclifie-Brown on the general methods of sociological inquiry as applied to simple societies. Here are given in condensed form the results of field investigations by different observers into the political systems of eight widely distributed African peoples. These studies cover South Africa (Zulu, Ngwato of Bechuanaland, Bemba of North-Eastern Rhodesia), East Africa (Ankole of Uganda, and Bantu Kavirondo), West Africa (Kede, Tallensi), and Sudan (Nuer). Although not completely comprehensive as to type, as the editors point out, the eight societies afiord a general picture of the main forms of African political systems.

The eight types of political systems here described fall into two groups. Of these, the first inoludes those in which the maintenance of law and order and the dispensation of justice are dependent upon a centralized organization culminating in a paramount chief who rules with the assistance of a council and through a number of regionally distributed subordinate chiefs. Such a system, obviously, lends itself to the requirements of European rule. In the second group there is no such centralized organization with a supreme head. The society is organized in accordance with lineage and is 'segmented', each group being autonomous and independent of the others. Law and order are maintained by a nice adjustment of interests at each and every point of contact between groups. In such a system, European control, either through lack of understanding or through administrative requirement-sometimes both--has constituted headmen functioning as do the chiefs of the first group in relations between administration and people.

In estimating the value and effect of Indirect Rule as a mode of administration which has as its object that of introducing the minimum of disturbance into the economy of tribal life through European control, there is a number of important considerations to be taken into account, of which the most important is the fact that the power of the paramount chief is by no means absolute. By

* African Political Systems. Edited by Dr. M. Fortes and Dr. E. E. Evans-Pritchard. (Published for the International Institute of African Languages and Cultures.) Pp. xxiii +301. (London: Oxford University Press, 1940.) 15s. net. an extensive system of check and countercheck - the council, queen's courts, the rights, duties and interests of officials and subordinate chiefs and the like-there is throughout the community a balance of power which not only limits the power of the chief, but also ensures the continuity and preservation of custom, secures the effective representation of every grade of society in the general direction of af airs, and in the ultimate analysis places what would correspond to 'sovereignty' in the hands of the people. It is inevitable that this delicate adjustment should suffer dislocation under European control. Even Indirect Rule cannot avert the disturbance involved in depriving the chief of the power of initiating legislation independently and of making war. In the result, in the societies of the first category mentioned above, the chief has become a bufier between administration and people, who on whichever side his sympathies lie-and usually and naturally they are with his own kinis suspect to both, or at least his actions subjected to strict supervision on one side, carping criticism on the other, even or most often when officially dictated. No less important is the fact that the religious and symbolic bond centring in the chiefly office, which so often binds together African societies of the centralized type, is weakened beyond repair.

It is inevitable that some measure of friction and disturbance must arise in African societies when under European control ; and Indirect Rule, which aims at respecting African institutions, so far would seem to have been the most successful in minimizing its effects. Where we now stand, however, in our relations with other powers ruling in the greater part of Africa, opportunity will be afforded, when other preoccupations are less insistent, to consider what forms of control will best promote the future prosperity of the African. To attain this end there are certain essentials. First, full and free cooperation between all European powers administering African territory, not necessarily to secure uniformity in administrative method, but rather to ensure that such forms of rule as are applied should be most suitable to the character and circumstances of the governed in each instance. Secondly, and following from this, that decision should be made only after close intensive study of the respective native institutions, cultures and modes of thought; and thirdly, since through European contact and control change must come, that that change should be canalized in such direction as sociological and economic research may indicate as likely to enable the African best to bear his part in world economy. The severest stricture on Indirect Rule which its critics are in a position to make is that it lacks direction. 